\title{
Revisiting the drug interaction between tamoxifen and SSRI antidepressants
}

\author{
(9) (1) $\Theta$ OPEN ACCESS \\ Women taking tamoxifen should play safe and avoid antidepressants that inhibit CYP2D6
}

\author{
David Juurlink professor and head \\ Division of Clinical Pharmacology and Toxicology, University of Toronto, ON, Canada
}

Few topics in therapeutics are more vexing than drug interactions. They number in the thousands, involve confusing terminology, and are rarely supported by evidence stronger than case reports and volunteer studies. ${ }^{1}$ It's not surprising, therefore, that experts disagree on which interactions are serious and which ones are not. ${ }^{2}$ And yet their importance is undeniable because they can cause serious morbidity or even death, despite epitomizing, in theory at least, avoidable drug related harm.

Over the past decade, few drug interactions have been as controversial as those involving tamoxifen and selective serotonin reuptake inhibitor (SSRI) antidepressants, ${ }^{3}$ explored yet again by Donneyong and colleagues in a linked study (doi:10.1136/bmj.i5014). ${ }^{4}$ On its surface, the issue seems straightforward: as a prodrug, tamoxifen requires conversion to active metabolites, the most important of which is endoxifen. This process is influenced by cytochrome-P450 isoenzyme 2D6 (CYP2D6), an enzyme characterized by marked variability from person to person. Some SSRIs but not others inhibit CYP2D6, conceivably attenuating or even abolishing the benefits of tamoxifen.

The importance of this potential interaction is amplified by three factors. First, tamoxifen is a monumental treatment, conferring dramatic reductions in breast cancer recurrence and associated mortality. ${ }^{5}$ Second, antidepressants are often co-prescribed with tamoxifen for extended periods, ${ }^{6}$ in part because depression often coexists with breast cancer and in part to offset vasomotor symptoms induced by tamoxifen. ${ }^{7}$ Third, and in contrast with most drug interactions, the consequences are delayed by years and manifest simply as treatment failure, undermining causal attribution at the patient level.

Why does the interaction between tamoxifen and SSRIs remain controversial? One reason is that tamoxifen's pharmacokinetic fate involves processes other than CYP2D6. ${ }^{8}$ Another is that studies of the relation between CYP2D6 activity and outcomes in women receiving tamoxifen yield remarkably inconsistent results. ${ }^{9}$ Finally, with some exceptions, ${ }^{10}{ }^{11}$ observational studies show little evidence that use of antidepressants is associated with adverse outcomes in women receiving tamoxifen. ${ }^{12-14}$

Donneyong and colleagues used data from five US health insurance databases to study women already being treated with an SSRI at the outset of treatment with tamoxifen or who received an SSRI later during its course. ${ }^{4}$ Over a median follow-up of about two years, they found no difference in overall mortality among women receiving SSRIs that inhibit CYP2D6 (paroxetine and fluoxetine) relative to SSRIs that do not (citalopram, escitalopram, fluvoxamine and sertraline).

These findings are unsurprising, if for no other reason than follow-up was too brief for any differential survival to show up. ${ }^{5}$ Studying total mortality rather than cancer specific outcomes further diminished the investigators' ability to discern signal from noise. Consequently, this study does little to disprove a meaningful interaction between tamoxifen and CYP2D6 inhibitors. It does, however, illustrate just how challenging such studies can be. Pharmacoepidemiology is a relative newcomer to the science of drug interactions, with most studies exploring short term toxicities after the co-prescription of drugs with well established interactions. ${ }^{15-17}$ In contrast, the interaction between tamoxifen and CYP2D6 inhibiting SSRIs is characterized by an elusive outcome (treatment failure), a long latent period, and many other factors (including non-adherence, therapeutic switching, CYP2D6 polymorphisms, dose-response effects, ${ }^{18}$ variable mechanisms and degrees of inhibition, ${ }^{19}$ and a probable endoxifen threshold below which treatment failure is more likely ${ }^{20}$ ) that collectively attenuate any signal that might exist. For these reasons, the tamoxifen-SSRI interaction is perhaps the most difficult drug interaction to explore using the techniques of pharmacoepidemiology.

Where does this leave patients and clinicians? In my view it is premature to dismiss an interaction between tamoxifen and SSRIs, particularly given the stakes and the ease with which harm can be mitigated. We know tamoxifen prevents recurrence and death from breast cancer, ${ }^{5}$ that endoxifen is its dominant metabolite, and that CYP2D6 plays an important role in its 
generation. These observations alone make it difficult to justify the extended co-prescription of tamoxifen with strong CYP2D6 inhibitors. We also know that switching antidepressants can result in markedly higher endoxifen concentrations. ${ }^{21}$ Not only is this intuitively desirable, it affords clinicians and patients some therapeutic leeway.

I suggest the co-prescribing of antidepressants and tamoxifen be guided by three principles. First, antidepressants should be selectively prescribed to patients likely to benefit. This is plainly true of all treatments, but it warrants explicit mention here in view of the limited utility of SSRIs in people with mild to moderate depression. ${ }^{22}$ Second, controversy notwithstanding, pragmatism dictates preferential avoidance of antidepressants known to inhibit CYP2D6, including fluoxetine, duloxetine, bupropion, and especially paroxetine.$^{23}$ Sertraline, citalopram, escitalopram, and venlafaxine impart lesser degrees of inhibition and are reasonable alternatives. Finally, for women already taking tamoxifen with a known CYP2D6 inhibitor, any change in treatment should be gradual to minimize the risks of SSRI withdrawal and the idiosyncratic adverse effects commonly seen on initiation of treatment.

Competing interests: I have read and understood the BMJ Group policy on declaration of interests and declare the following interests: None.

Provenance and peer review: Commissioned; not peer reviewed.

1 Juurlink DN. Drug-drug interactions: where do we go from here? J Am Pharm Assoc (2003) 2004:44:128, 131-2, 134. doi:10.1331/154434504773062573 pmid:15098846.

2 Abarca J, Malone DC, Armstrong EP, et al. Concordance of severity ratings provided in four drug interaction compendia. J Am Pharm Assoc (2003) 2004;44:136-41. doi:10.1331/ 154434504773062582 pmid:15098847.

3 Donneyong MM, Bykov K, Bosco-Levy P, et al. Risk of mortality with concomitant use of tamoxifen and selective serotonin reuptake inhibitors: multi-database cohort study. BMJ 2016;354:i5014

4 Andrade C. Breast cancer and antidepressant use. J Clin Psychiatry 2012;73:e1156-7. doi:10.4088/JCP.12f08054 pmid:23059156.

5 Davies C, Godwin J, Gray R, et al. Early Breast Cancer Trialists' Collaborative Group (EBCTCG). Relevance of breast cancer hormone receptors and other factors to the efficacy of adjuvant tamoxifen: patient-level meta-analysis of randomised trials. Lancet 2011;378:771-84. doi:10.1016/S0140-6736(11)60993-8 pmid:21802721.

6 Dusetzina SB, Alexander GC, Freedman RA, Huskamp HA, Keating NL. Trends in co-prescribing of antidepressants and tamoxifen among women with breast cancer, 2004-2010. Breast Cancer Res Treat 2013;137:285-96. doi:10.1007/s10549-012-2330z pmid:23149465.

7 Johns C, Seav SM, Dominick SA, et al. Informing hot flash treatment decisions for breas cancer survivors: a systematic review of randomized trials comparing active interventions.
Breast Cancer Res Treat 2016;156:415-26. doi:10.1007/s10549-016-3765-4 pmid: 27015968.

8 Cronin-Fenton DP, Damkier P, Lash TL. Metabolism and transport of tamoxifen in relation to its effectiveness: new perspectives on an ongoing controversy. Future Oncol 2014;10:107-22. doi:10.2217/fon.13.168 pmid:24328412.

9 Hertz DL, McLeod HL, Irvin WJ Jr. Tamoxifen and CYP2D6: a contradiction of data. Oncologist 2012;17:620-30. doi:10.1634/theoncologist.2011-0418 pmid:22531359.

10 Chubak J, Bowles EJ, Yu O, Buist DS, Fujii M, Boudreau DM. Breast cancer recurrence in relation to antidepressant use. Cancer Causes Control 2016;27:125-36. doi:10.1007/ s10552-015-0689-y pmid:26518198.

11 Kelly CM, Juurlink DN, Gomes T, et al. Selective serotonin reuptake inhibitors and breast cancer mortality in women receiving tamoxifen: a population based cohort study. BMJ 2010;340:c693. doi:10.1136/bmj.c693 pmid:20142325.

12 Lash TL, Cronin-Fenton D, Ahern TP, et al. Breast cancer recurrence risk related to concurrent use of SSRI antidepressants and tamoxifen. Acta Oncol 2010;49:305-12. doi: 10.3109/02841860903575273 pmid:20156115.

13 Dezentjé VO, van Blijderveen NJ, Gelderblom H, et al. Effect of concomitant CYP2D6 inhibitor use and tamoxifen adherence on breast cancer recurrence in early-stage breast cancer. J Clin Oncol 2010;28:2423-9. doi:10.1200/JCO.2009.25.0894 pmid:20385997.

14 Haque R, Shi J, Schottinger JE, et al. Tamoxifen and Antidepressant Drug Interaction in a Cohort of 16,887 Breast Cancer Survivors. J Natl Cancer Inst 2015;108:djv337. doi:10. 1093/jnci/djv337 pmid:26631176.

15 Antoniou T, Gomes T, Mamdani MM, et al. Trimethoprim-sulfamethoxazole induced hyperkalaemia in elderly patients receiving spironolactone: nested case-control study. BMJ 2011;343:d5228. doi:10.1136/bmj.d5228 pmid:21911446.

16 Juurlink DN, Mamdani M, Kopp A, Laupacis A, Redelmeier DA. Drug-drug interactions among elderly patients hospitalized for drug toxicity. JAMA 2003;289:1652-8. doi:10.1001/ jama.289.13.1652 pmid:12672733

17 Wright AJ, Gomes T, Mamdani MM, Horn JR, Juurlink DN. The risk of hypotension following co-prescription of macrolide antibiotics and calcium-channel blockers. CMAJ 2011;183:303-7. doi:10.1503/cmaj.100702 pmid:21242274.

18 Hertz DL, Deal A, Ibrahim JG, et al. Tamoxifen Dose Escalation in Patients With Diminished CYP2D6 Activity Normalizes Endoxifen Concentrations Without Increasing Toxicity. Oncologist 2016;21:795-803. doi:10.1634/theoncologist.2015-0480 pmid:27226358.

19 Bertelsen KM, Venkatakrishnan K, Von Moltke LL, Obach RS, Greenblatt DJ. Apparent mechanism-based inhibition of human CYP2D6 in vitro by paroxetine: comparison with fluoxetine and quinidine. Drug Metab Dispos 2003;31:289-93. doi:10.1124/dmd.31.3. 289 pmid: 12584155.

20 Madlensky L, Natarajan L, Tchu S, et al. Tamoxifen metabolite concentrations, CYP2D6 genotype, and breast cancer outcomes. Clin Pharmacol Ther 2011;89:718-25. doi:10. 1038/clpt.2011.32 pmid:21430657

21 Binkhorst L, Bannink M, de Bruijn P, et al. Augmentation of Endoxifen Exposure in Tamoxifen-Treated Women Following SSRI Switch. Clin Pharmacokinet 2016;55:249-55. doi:10.1007/s40262-015-0315-x pmid:26446141.

22 Fournier JC, DeRubeis RJ, Hollon SD, et al. Antidepressant drug effects and depression severity: a patient-level meta-analysis. JAMA 2010;303:47-53. doi:10.1001/jama.2009. 1943 pmid:20051569.

23 Jin Y, Desta Z, Stearns V, et al. CYP2D6 genotype, antidepressant use, and tamoxifen metabolism during adjuvant breast cancer treatment. J Natl Cancer Inst 2005;97:30-9. doi:10.1093/jnci/dji005 pmid:15632378.

Published by the BMJ Publishing Group Limited. For permission to use (where not already granted under a licence) please go to http://group.bmj.com/group/rights-licensing/ permissions

This is an Open Access article distributed in accordance with the Creative Commons Attribution Non Commercial (CC BY-NC 3.0) license, which permits others to distribute, remix, adapt, build upon this work non-commercially, and license their derivative works on different terms, provided the original work is properly cited and the use is non-commercial. See: http://creativecommons.org/licenses/by-nc/3.0/. 